\section{JURNAL EKONOMI EFEKTIF}

ISSN : $2622-8882$, E-ISSN : 2622-9935

Jurnal Ekonomi Efektif, Vol. 2, No. 4, Juli 2020

@.Prodi Manajemen Fakultas Ekonomi Universitas

Pamulang

\title{
PENGARUH KUALITAS PRODUK TERHADAP KEPUTUSAN PEMBELIAN KONSUMEN PADA PT. KARUNIA PRIMA SEJATI DI BANDUNG
}

\author{
Kosasih \\ Universitas Sangga Buana, Bandung, Jawa Barat, Indonesia \\ *kosasih@usbypkp.ac.id
}

\begin{abstract}
ABSTRAK
Penelitian ini bertujuan untuk mengetahui pengaruh kualitas produk terhadap keputusan pembelian konesumen pada PT. Karunia Prima Sejati Di Bandung. Metode yang digunakan adalah explanatory research dengan sampel sebanyak 100 responden. Teknik analisis menggunakan analisis statistik dengan pengujian regresi, korelasi, determinasi dan uji hipotesis. Hasil penelitian ini variabel kualitas produk diperoleh nilai rata-rata skor sebesar 3,415 dengan kriteria baik. Variabel keputusan pembelian diperoleh nilai rata-rata skor sebesar 3,839 dengan kriteria baik. Kualitas produk berpengaruh positif dan signifikan terhadap keputusan pembelian dengan nilai persamaan regresi $\mathrm{Y}=8,515+0,875 \mathrm{X}$, dan nilai koefisien korelasi 0,791 atau memiliki tingkat hubungan yang kuat dengan nilai determinasi $62,6 \%$. Uji hipotesis diperoleh signifikansi $0,000<0,05$.
\end{abstract}

Kata Kunci: Kualitas Produk, Keputusan Pembelian.

\section{ABSTRACT}

This study aims to determine the effect of product quality on consumer purchasing decisions at PT. Karunia Prima Sejati in Bandung. The method used is explanatory research with a sample of 100 respondents. The analysis technique uses statistical analysis with regression testing, correlation, determination and hypothesis testing. The results of this research variable product quality obtained an average score of 3,415 with good criteria. The purchase decision variable obtained an average score of 3.839 with good criteria. Product quality has a positive and significant effect on purchasing decisions with a regression equation value of $Y=8,515+0.875 X$, and a correlation coefficient value of 0.791 or has a strong level of relationship with a determination value of $62.6 \%$. Hypothesis testing obtained a significance of $0.000<0.05$.

Keywords: Product Quality, Purchasing Decision. 


\section{PENDAHULUAN}

\section{A. Latar Belakang Masalah}

Pada era globalisasi ini banyak berbagai macam perusahaan yang berkembang pesat dari tahun ke tahun, dan semua ini dimulai bedasarkan untuk memuaskan kebutuhan konsumen hingga memenuhi keinginan konsumen, kondisi ini pun tidak dapat ditahan sehingga banyak bermunculan produk-produk baru yang siap untuk dapat memuaskan kebutuhan dan keinginan konsumen, karena pertumbuhan dunia usaha yang semakin maju tentunya memerlukan suatu pengelola yang lebih baik agar perusahaan dapat lebih berkembang lagi. Perusahaan selalu berupaya mempersiapkan dan juga mengembangkan perusahaannya ke arah yang lebih baik dari sebelumnya, terutama untuk dapat bertahan dari ancaman-ancaman dari saingan perusahaan. Banyak perusahaan yang berlomba-lomba untuk meningkatkan kualitas perusahaan agar dapat menjadi perusahaan yang berkompeten di dalam dunia bisnis. Perkembangan yang dilakukan perusahaan tidak hanya di dalam perusahaan melainkan juga diluar perusahaan.

Konsumen memiliki kepribadian yang berbeda-beda dalam memilih atau menyingkapi suatu obyek yang sama, oleh karena itu banyak dari para ahli mengatakan bahwa konsumen adalah seseorang yang sangat unik. Selain itu konsumen berasal dari beberapa segmen, sehingga keinginan mereka dan kebutuhan mereka pun cenderung berbeda. Selain itu masih banyak faktor-faktor yang mempengaruhi keputusan pembelian. Perusahaan perlu memahami perilaku konsumen terhadap produk yang ditawarkan kepada konsumen, dan selanjutnya perlu untuk menarik minat konsumen untuk dapat membeli produk yang akan ditawarkan. Kehidupan masyarakat modern ini memperngaruhi pola perilaku masyarakat dalam pembelian. Karena kehidupan yang moderen ini identik dengan gaya hidup yang terus menerus mengikuti perkembangan jaman serta akan selalu berkembang tanpa adanya batasan, dan dalam kondisi saat ini, keputusan memilih merek turut juga berperan penting dalam gaya hidup yang modern, sehingga keinginan untuk membeli produk yang bermerek turut berpengaruh pada pola konsumsi seseorang. Meskipun banyak produk yang tersebar di pasar, dan lebih sering kita temukan adalah produk yang sejenis sehingga terutama produk pesaing, semuanya bergatung dari ekuitas konsumen terhadap produk dan faktor lainnya. Apabila konsumen telah memahami benar tentang produk yang diyakininya, maka secara otomatis produk yang diyakininya semakin kuat di benak konsumen.

Ekuitas produk dapat dibentuk melalui informasi, baik dari pendapat teman atau pengalaman sendiri, dan jika konsumen memiliki persepsi yang baik terhadap produk, akan mempengaruhi terbentuknya pilihan produk yang akan dibeli, selanjutnya akan membentuk sikap positif yang pada gilirannya akan mempengaruhi keputusan pembelian, hal ini sejalan dengan informasi yang diperoleh dan diproses konsumen akan membentuk prefensi seseorang terhadap suatu obyek. Preferensi akan membentuk sikap konsumen terhadap suatu obyek yang pada gilirannya sikap ini seringkali secara langsung akan mempengaruhi apakah konsumen akan membeli suatu produk atau tidak. Presepsi konsumen terhadap produk akan membentuk preferensi dan sikap yang pada gilirannya akan mempengaruhi keputusan untuk membeli atau tidak. Produk memberikan kesan atau nilai dalam beberapa bentuk diantaranya adalah alasan untuk membeli. Niat untuk melakukan pembelian dapat terbentuk dari sikap konsumen terhadap bauran pemasaran diantaranya melalui promosi.

Kegiatan promosi yang dilakukan PT. Karunia Prima Sejati diantaranya melalui periklanan, potongan harga dan personal selling. Keputusan pembelian konsumen dalam pembelian produk PT. Karunia Prima Sejati dapat dipengaruhi dari produk, harga produk dan promosi produk. Bedasarkan uraian diatas yang menjadi pokok permasalahan adalah 
sejauh mana produk, harga, promosi berpengaruh terhadap keputusan pembelian produk kimia PT. Karunia Prima Sejati Di Bandung, karena PT. Karunia Prima Sejati kurang menyadarinya terhadap pengaruh produk, harga dan promosi, selain itu juga mengingatkan bahwa kepuasan konsumen adalah sesuatu hal yang penting bagi perusahaan, oleh karena itu penulis memutuskan judul penelitian yaitu "Pengaruh Kualitas ProdukTerhadap Keputusan Pembelian konsumen di PT. Karunia Prima Sejati Di Bandung”,

\section{B. Rumusan Masalah}

1. Bagaimana kualitas produk pada PT. Karunia Prima Sejati Di Bandung?.

2. Bagaimana keputusan pembelian pada PT. Karunia Prima Sejati Di Bandung ?.

3. Adakah pengaruh antara kualitas produk terhadap keputusan pembelian pada PT. Karunia Prima Sejati Di Bandung?.

\section{Tujuan Penelitian}

1. Untuk mengetahui kondisi kualitas produk pada PT. Karunia Prima Sejati Di Bandung.

2. Untuk mengetahui kondisi keputusan pembelian pada PT. Karunia Prima Sejati Di Bandung.

3. Untuk mengetahui pengaruh kualitas produk terhadap keputusan pembelian pada PT. Karunia Prima Sejati Di Bandung.

\section{TINJAUAN PUSTAKA}

\section{Kualitas Produk}

Menurut Kotler dalam Tjiptono (2019) menyatakan bahwa "Kualitas produk adalah tingkat keunggulan yang diharapkan dan pengendalian atas tingkat keunggulan tersebut untuk memenuhi keinginan pelanggan”.

\section{Keputusan Pembelian}

Menurut Kotler dan Amstrong (2019) berpendapat "perilaku konsumen merupakan sebuah pendekatan penyesuaian masalah yang terdiri dari lima tahap yang dilakukan konsumen. Kelima tahap tersebut adalah pengenalan masalah, pencarian informasi, evaluasi alternatif, keputusan pembelian, dan perilaku pasca pembelian".

\section{METODE PENELITIAN}

\section{Populasi}

Populasi dalam penelitian ini berjumlah 100 responden PT. Karunia Prima Sejati Di Bandung

\section{Sampel}

Teknik pengambilan sampling dalam penelitian ini adalah sampel jenuh, dimana semua anggota populasi dijadikan sebagai sampel. Dengan demikian sampel dalam penelitian ini sampel yang digunakan berjumlah 100 responden.

\section{Jenis Penelitian}

Jenis penelitian yang dipakai adalah asosiatif, dimana tujuannya adalah untuk mengetahui atau mencari keterhubungan antara variabel independen terhadap variabel dependennya

\section{Metode Analisis Data}

Dalam menganalisis data digunakan uji validitas, uji reliabilitas, analisis regresi linier sederhana, analisis koefisien korelasi, analisis koefisien determinasi dan pengujian 
hipotesis.

\section{HASIL PENELITIAN}

\section{Analisis Deskriptif}

Pada pengujian ini digunakan untuk mengetahui skor minimum dan maksimum skor tertinggi, ratting score dan standar deviasi dari masing-masing variabel. Adapun hasilnya sebagai berikut:

Tabel 1. Hasil Analisis Descriptive Statistics

\begin{tabular}{ll|r|r|r|r}
\multicolumn{7}{c}{ Descriptive Statistics } \\
& N & Minimum & Maximum & Mean & Std. Deviation \\
\hline Kualitas Produk (X) & 100 & 28 & 44 & 34.15 & 3.807 \\
\hline Keputusan Pembelian (Y) & 100 & 29 & 49 & 38.39 & 4.209 \\
\hline Valid N (listwise) & 100 & & & & \\
\hline
\end{tabular}

Kualitas produk diperoleh varians minimum sebesar 28 dan varians maximum 44 dengan ratting score sebesar 3,415 dengan standar deviasi 3,607. Skor ini termasuk pada rentang sakala 3,40 - 4,19 dengan kriteria baik atau setuju.

Keputusan pembelian diperoleh varians minimum sebesar 29 dan varians maximum 49 dengan ratting score sebesar 3,839 dengan standar deviasi 4,209. Skor ini termasuk pada rentang sakala 3,40 - 4,19 dengan kriteria baik atau setuju.

\section{Analisis Kuantitatif.}

Pada analisis ini dimaksudkan untuk mengetahui pengaruh variabel independen terhadap variabel dependen. Adapun hasil pengujian sebagai berikut:

\section{a. Analisis Regresi Linier Sederhana}

Uji regresi ini dimaksudkan untuk mengetahui perubahan variabel dependen jika variabel independen mengalami perubahan. Adapun hasil pengujiannya sebagai berikut:

Tabel 2. Hasil Pengujian Regresi Linier Sederhana

\begin{tabular}{|c|c|c|c|c|c|c|}
\hline \multicolumn{7}{|c|}{ Coefficients $^{a}$} \\
\hline & & \multicolumn{2}{|c|}{$\begin{array}{l}\text { Unstandardized } \\
\text { Coefficients }\end{array}$} & \multirow{2}{*}{$\begin{array}{c}\text { Standardize } \\
\text { d } \\
\text { Coefficients } \\
\text { Beta }\end{array}$} & \multirow[b]{2}{*}{$\mathrm{t}$} & \multirow[b]{2}{*}{ Sig. } \\
\hline \multicolumn{2}{|c|}{ Model } & $\mathrm{B}$ & Std. Error & & & \\
\hline & (Constant) & 8.515 & 2.346 & & 3.629 & .000 \\
\hline & Kualitas Produk (X) & .875 & .068 & .791 & 12.810 & .000 \\
\hline
\end{tabular}

a. Dependent Variable: Keputusan Pembelian (Y)

Berdasarkan hasil pengujian pada tabel di atas, diperoleh persamaan regresi $\mathrm{Y}=$ $8,515+0,875 X$. Dari persamaan tersebut dijelaskan sebagai berikut:

1) Konstanta sebesar 8,515 diartikan jika kualitas produk tidak ada, maka telah terdapat nilai keputusan pembelian sebesar 8,515 point.

2) Koefisien regresi kualitas produk sebesar 0,875 , angka ini positif artinya setiap ada peningkatan kualitas produk sebesar 0,875 point maka keputusan pembelian juga akan mengalami peningkatan sebesar 0,875 point.

\section{b. Analisis Koefisien Korelasi}

Analisis koefisien korelasi dimaksudkan untuk mengetahui tingkat kekuatan hubungan dari variabel independen terhadap variabel dependen. Adapun hasil pengujian sebagai berikut:

Tabel 3. Hasil Pengujian Koefisien Korelasi Kualitas Produk Terhadap Keputusan 
Pembelian.

\begin{tabular}{|c|c|c|c|}
\hline \multicolumn{4}{|c|}{ Correlations $^{b}$} \\
\hline & & $\begin{array}{l}\text { Kualitas Produk } \\
\text { (X) }\end{array}$ & $\begin{array}{c}\text { Keputusan } \\
\text { Pembelian (Y) }\end{array}$ \\
\hline \multirow[t]{2}{*}{ Kualitas Produk (X) } & Pearson Correlation & 1 & $.791^{\star *}$ \\
\hline & Sig. (2-tailed) & & .000 \\
\hline \multirow[t]{2}{*}{ Keputusan Pembelian (Y) } & Pearson Correlation & $.791^{\star *}$ & 1 \\
\hline & Sig. (2-tailed) & .000 & \\
\hline
\end{tabular}

Berdasarkan hasil pengujian diperoleh nilai korelasi sebesar 0,791 artinya kualitas produk memiliki hubungan yang kuat terhadap keputusan pembelian.

\section{c. Analisis Koefisien Determinasi}

Analisis koefisien determinasi dimaksudkan untuk mengetahui besarnya persentase pengaruh dari variabel independen terhadap variabel dependen. Adapun hasil pengujian sebagai berikut:

Tabel 4. Hasil Pengujian Koefisien Determinasi Kualitas Produk Terhadap Keputusan Pembelian.

\section{Model Summary}

\begin{tabular}{lrr|rr|rr} 
Model & $\mathrm{R}$ & $\mathrm{R}$ Square & $\begin{array}{c}\text { Adjusted R } \\
\text { Square }\end{array}$ & $\begin{array}{c}\text { Std. Error of the } \\
\text { Estimate }\end{array}$ \\
\hline 1 & $.791^{\mathrm{a}}$ & .626 & .622 & 2.587 \\
\hline
\end{tabular}

a. Predictors: (Constant), Kualitas Produk $(X)$

Berdasarkan hasil pengujian diperoleh nilai determinasi sebesar 0,626 artinya kualitas produk memiliki kontribusi pengaruh sebesar 62,6\% terhadap keputusan pembelian, sedangkan sisanya sebesar $37,4 \%$ dipengaruhi oleh faktor lain yang tidak dilakukan penelitian.

\section{d. Uji Hipotesis}

Pengujian hipotesis dengan uji $\mathrm{t}$ digunakan untuk mengetahui hipotesis mana yang diterima.

Rumusan hipotesis: Terdapat pengaruh yang signifikan kualitas produk terhadap keputusan pembelian.

Tabel 5. Hasil Uji Hipotesis Kualitas produk Terhadap Keputusan Pembelian.

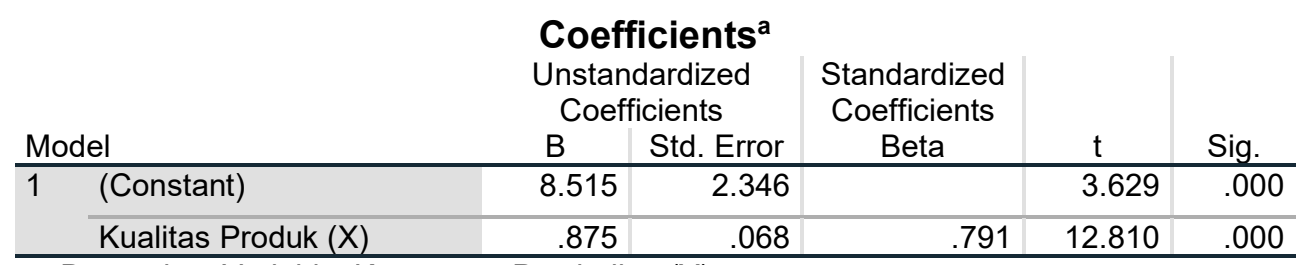

a. Dependent Variable: Keputusan Pembelian (Y)

Berdasarkan hasil pengujian pada tabel di atas, diperoleh nilai $\mathrm{t}$ hitung $>\mathrm{t}$ tabel atau $(7,809>1,987)$, dengan demikian hipotesis yang diajukan bahwa terdapat pengaruh yang signifikan atara kualitas produk terhadap keputusan pembelian diterima.

\section{Pembahasan Hasil Penelitian}

\section{Kondisi Jawaban Responden Variabel Kualitas Produk}

Berdasarkan jawaban responden, variabel kualitas produk diperoleh ratting score sebesar 3,415 berada di rentang skala 3,40 - 4,19 dengan kriteria baik atau setuju. 


\section{Kondisi Jawaban Responden Variabel Keputusan Pembelian}

Berdasarkan jawaban responden, variabel keputusan pembelian diperoleh ratting score sebesar 3,839 berada di rentang skala 3,40-4,19 dengan kriteria baik atau setuju.

\section{Pengaruh Kualitas produk Terhadap Keputusan Pembelian}

Kualitas produk berpengaruh signifikan terhadap keputusan pembelian dengan persamaan regresi $Y=8,515+0,875 X$, nilai korelasi sebesar 0,791 atau memiliki hubungan yang kuat dengan kontribusi pengaruh sebesar $62,6 \%$. Pengujian hipotesis diperoleh nilai $t$ hitung $>\mathrm{t}$ tabel atau $(7,809>1,987)$. Dengan demikian hipotesis yang diajukan bahwa terdapat berpengaruh signifikan antara kualitas produk terhadap keputusan pembelian diterima.

\section{KESIMPULAN DAN SARAN}

1. Kesimpulan

a. Variabel kualitas produk diperoleh ratting score sebesar 3,415 berada di rentang skala 3,40 - 4,19 dengan kriteria baik atau setuju.

b. Variabel keputusan pembelian diperoleh ratting score sebesar 3,839 berada di rentang skala 3,40-4,19 dengan kriteria baik atau setuju.

c. Kualitas produk berpengaruh signifikan terhadap keputusan pembelian dengan persamaan regresi $\mathrm{Y}=8,515+0,875 \mathrm{X}$, nilai korelasi sebesar 0,791 atau kuat dan kontribusi pengaruh sebesar $62,6 \%$ sedangkan sisanya sebesar $37,4 \%$ dipengaruhi faktor lain. Uji hipotesis diperoleh nilai t hitung $>\mathrm{t}$ tabel atau $(7,809>1,987)$.

\section{Saran}

Berdasarkan hasil penelitian di atas, maka penulis memberikan saran sebagai berikut:

a. ditingkatkan supaya konsumen bisa merasa puas. Perusahaan lebih menerima masukan dari konsumen sebagai bahan pertimbangan untuk mengembangkan lagi produknya sehingga pilihan yang tersedia pun semakin banyak dan beragam.

b. Perlu diadakan survei pasar secara periodik, baik terhadap pelanggan maupun perusahaan pesaing. Pada akhirnya perusahaan selalu mengetahui apa yang di butuhkan (Needs), diinginkan (Wants) dan di harapkan (Expectations) oleh pelanggan, sehingga mampu menciptakan suatu kepuasan bagi pelanggan

c. Penelitian ini dapat dilanjutkan oleh penelitian lain dengan menggunakan variable independen yang lain.

\section{DAFTAR PUSTAKA}

Erlangga, H, et al. (2019). Pengaruh Kegiatan Promosi Terhadap Keputusan Pembelian Konsumen Pada PT. Modise Busana Sejati Di Bandung. Jurnal Ekonomi Efektif, 1(4).

Jasmani, J., \& Paeno, P. (2019). The Effect of Leadership and Competence on Lecturer Performance and Its Implications on Student Learning Motivation at Pamulang University. International Journal of Advances in Social and Economics, 1(4).

Jasmani, J., \& Sunarsi, D. (2020). The Influence of Product Mix, Promotion Mix and Brand Image on Consumer Purchasing Decisions of Sari Roti Products in South Tangerang. PINISI Discretion Review, 1(1), 165-174.

Ilham, D. (2014). Implementasi Nilai-Nilai Keagamaan pada Mata Pelajaran Umum dalam Upaya Peningkatan Akhlak Peserta Didik di MAN Malili Kabupaten Luwu 
Timur (Doctoral dissertation, STAIN/IAIN Palopo).

Ilham, D. (2019). Implementing Local Wisdom Values in Bride and Groom Course at KUA Bara SubDistrict, Palopo City. Jurnal Konsepsi, 8(1), 1-9.

Ilham, D. (2019). Menggagas Pendidikan Nilai dalam Sistem Pendidikan

Nasional. Didaktika: Jurnal Kependidikan, 8(3), 109-122.

Kotler, Philip \& Amstrong, Garry, "Prinsip-Prinsip Pemasaran", Edisi Kedelapan, Penerbit Erlangga, Jakarta, 2001.

Kotler, Philip, "Manajemen Pemasaran di Indonesia”, Analisis, Perencanaan, Implementasi dan Pengendalian, Salemba Empat, Jakarta, 2001.

Kotler, Philip, “Manajemen Pemasaran”, Edisi Milenium, Penerbit PT Prehalindo, Jakarta, 2005.

Kotler, Philip. 1997. Manajemen Pemasaran: Analisis, Perencanaan, Implementasi, dan Kontrol. Diterjemahkan oleh: Hendra Teguh. SE, Ak. dan Ronny A. Rusli, SE, Ak. Jilid 1. Edisi Kesembilan. Jakarta: PT Prenhallindo.

Kotler, Philip. 2004. Manajemen Pemasaran 2, Edisi Millenium, PT.Ikrar Mandiri, Jakarta.Philip Kotler, Kevin Lane Keller "Manejemen Pemasaran", Edisi 13 Jilid 1, Penerbit PT.Indeks Gramedia, Jakarta, 2009.

Palmer, Adrian. 2001. Principles Of Services Marketing, Third Edition McGraw-Hill Companies, UK (United Kingdom).

Philip Kotler \& Kevin Lane Kelle, “Manajemen Pemasaran”, Edisi 13 Jilid 1, Penerbit PT Gelora Aksara Pratama, Jakarta, 2009.

Philip Kotler dan Gary Armstrong, "Prinsip-prinsip Pemasaran", Edisi12 Jilid 1, Penerbit PT. Gelora Aksara Pratama, Jakarta, 2008.

Ratminto \& Atik Septi Winarsih "Manejemen Pemasaran, Pengembangan Model Konseptual dan Standar Pelayanan Minimal”, Penerbit Pustaka Pelajar, 2010.

Schiffman, Leon G dan Leslie Lazar Kanuk, "Perilaku Konsumen", Edisi

Stanton, William J, "Prinsip Pemasaran”, Erlangga, Jakarta, 2001.

Sugiyono, "Metode Penelitian Kuantitatif Kualitatif dan R\&D”, Penerbit, Alfabeta, Bandung 2013.

Sugiyono, "Metode Penelitian Bisnis", Cetakan kedelapan, Penerbit CV. Alfabeta, Bandung, 2005.

Sugiyono, "Metode Penelitian Kuantitatif Kualitatif dan R\&D", Penerbit, Alfabeta, Bandung 2013.

Swastha, Basu \& Irawan, "Manajemen Pemasaran Modern”, Liberty, Yogyakarta, 2005.

Tjiptono, Fandi, Gregorius dan Dadi Adriana, "Pemasaran Strategik", Penerbit CV Andi Offset, Yogyakarta, 2008. 